\title{
Response of Lake Chemistry to Atmospheric Deposition and Climate in Selected Class I Wilderness Areas in the Western United States, 1993-2009
}

\section{The U.S. Geological Survey (USGS), in cooperation with the U.S. Department of Agriculture Forest Service (Forest Service), Air Resource Management, conducted a study to evaluate long- term trends in lake-water chemistry for 64 high-elevation lakes in selected Class I wilderness areas in Colorado, Idaho, Utah, and Wyoming during 1993 to 2009 (fig. 1). Understanding how and why lake chemistry is changing in mountain areas is essential for effectively managing and protecting high-elevation aquatic ecosystems. Trends in emissions, atmospheric deposition, and climate variables (air temperature and precipitation amount) were evaluated over a similar period of record. A main objective of the study was to determine if changes in atmospheric deposition of contaminants in the Rocky Mountain region have resulted in measurable changes in the chemistry of high- elevation lakes. A second objective was to investigate linkages between lake chemistry and air temperature and precipitation to improve understanding of the sensitivity of mountain lakes to climate variability.}

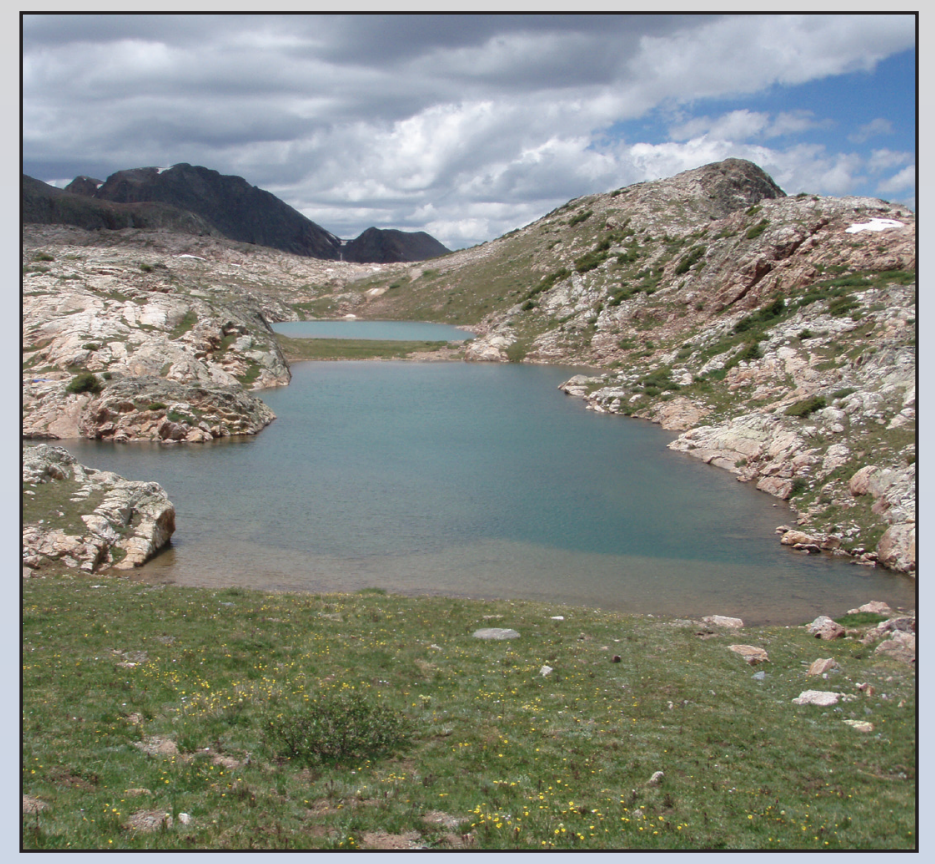

comprehensive analysis of the long-term dataset of lake chemistry collected in selected wilderness areas in Forest Service Regions 2 and 4 (Mast and Ingersoll, 2011).

\section{Data Sources and Methods of Analysis}

Types and sources of data used in the data analysis are listed in table 1. Emissions data for sulfur and nitrogen compounds were obtained from the U.S. Environmental Protection Agency National Emissions Inventory. Data describing the chemical composition of atmospheric deposition (wet and dry) were obtained from the National Atmospheric Deposition Program (NADP) and the USGS Rocky Mountain Snowpack Network (fig. 2). Climate data (air temperature and precipitation amount) were obtained from the National Resources Conservation Service Snow Telemetry network. Waterchemistry data were obtained from the Forest Service Air Resource Management program for 64 lakes in Colorado, Idaho, Utah, and Wyoming (fig. 1). Trends were computed using the nonparametric seasonal Kendall test and a modification referred to as the regional Kendall test (Helsel and others, 2006). 


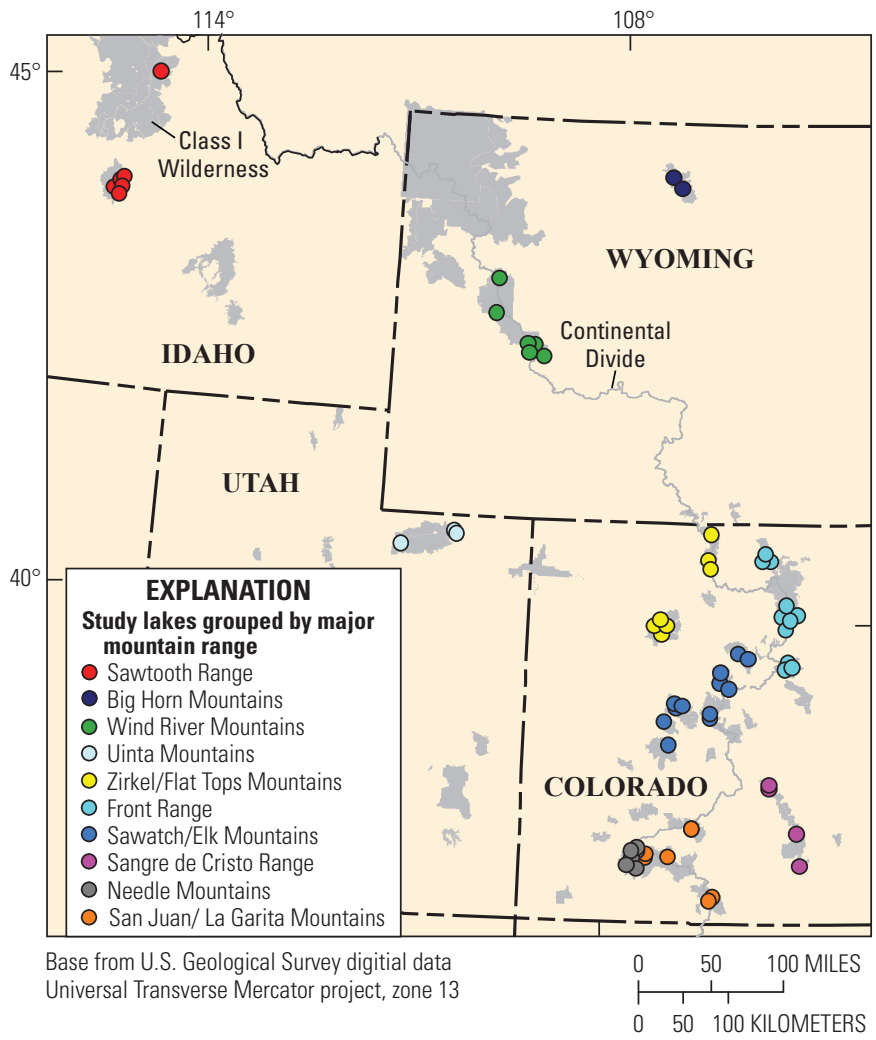

Figure 1. Location of study lakes grouped by major mountain range and Class I Wilderness Areas in Colorado, Idaho, Utah, and Wyoming.

\section{Major Findings}

\section{How have sulfur and nitrogen emissions changed in the Rocky Mountain region?}

Sulfur emissions have declined in the region by nearly 50 percent since the mid-1990s. Declines in nitrogen emissions have been more modest (around 25 percent) over the same period but are projected to increase substantially by 2018.

Emissions from anthropogenic activities are the main sources of sulfur and nitrogen contaminants reaching remote aquatic ecosystems in the Rocky Mountain region (Peterson and others, 1998; Burns, 2004). Sulfur dioxide ( $\left.\mathrm{SO}_{2}\right)$ emissions are almost entirely from stationary sources and have declined in the Rocky Mountain region (Arizona, Colorado, Idaho, Montana, New Mexico, Utah, and Wyoming) by nearly 50 percent since the mid-1990s (fig. 3) as a result of emissions controls placed on several large powerplants. In contrast to $\mathrm{SO}_{2}$, nitrogen oxide $\left(\mathrm{NO}_{\mathrm{x}}\right)$ and ammonia $\left(\mathrm{NH}_{3}\right)$ emissions largely are from mobile and nonpoint sources, such as vehicle emissions, oil and gas exploration and production, and agricultural activities. Available emission inventories indicate $\mathrm{NO}_{\mathrm{x}}$ from stationary and nonpoint sources in the Rocky Mountain region have decreased by as much as 25 percent since 1995, and $\mathrm{NH}_{3}$ emissions, which primarily result from agricultural activities, have shown a slight decrease. However, there is a high degree of uncertainty associated with emissions inventories from nonpoint sources, and the apparent trends in emissions may not be reliable.

Considering the dominant sources of sulfur and nitrogen emissions in the Rocky Mountains, there is greater potential for future increases in nitrogen than in sulfur emissions. Recent predictions by the Western Regional Air Partnership (WRAP) estimate only a 20-percent increase in $\mathrm{SO}_{2}$ emissions in the Western United States by 2018, compared to more than a 50-percent increase for $\mathrm{NO}_{\mathrm{x}}$ (Eastern Research Group, Inc., 2006). The substantial increase in $\mathrm{NO}_{\mathrm{x}}$ emissions primarily results from large projected increases in oil and gas production activity in the region, particularly in Colorado and New Mexico (Eastern Research Group, Inc., 2006).

\section{Have emission reductions affected sulfur and nitrogen deposition to high-elevation areas?}

Sulfate deposition to high-elevation areas has decreased throughout the region as a result of reductions in $\mathrm{SO}_{2}$ emissions. Nitrate deposition did not change substantially whereas ammonium deposition was found to be increasing, particularly at sites close to urban and agricultural areas.

Decreases in sulfate deposition were apparent across the Rocky Mountain region since the early 1990s. Sulfate concentrations in wet deposition decreased at 21 of the 23 high-elevation NADP stations (fig. 4). Percent declines at individual NADP stations ranged from 22 to 65 percent and averaged 43 percent, which is similar to the total reduction in $\mathrm{SO}_{2}$ emissions of 46 percent, providing strong evidence that precipitation chemistry is changing as a result of improvements in regional air quality. Because $\mathrm{SO}_{2}$ is converted to sulfuric acid in the atmosphere, the expectation is that declines in sulfate may be accompanied by declines in precipitation acidity. At 15 of the 23 NADP sites, there also were significant decreases in hydrogen-ion concentrations, suggesting a reduction in the acidity of precipitation also is occurring. Sulfate concentration trends were slightly weaker at snowpack than at NADP sites with only 30 percent of snowpack sites having statistically significant downward trends. Trends in sulfate deposition in the Rocky Mountain region are consistent

Table 1. Types and sources of data used in the study.

[Websites were accessed May 2011]

Data type

Emissions

Wet deposition

Snowpack

Climate

Lakes

\section{Source}

Web site

National Emissions Inventory (NEI)

National Atmospheric Deposition Program (NADP)

USGS Rocky Mountain Snowpack Network (RMSN)

Snow Telemetry Network (SNOTEL)

Forest Service Air Resource Management Program http://www.epa.gov/air/data/

http://nadp.sws.uiuc.edu/

http://co.water.usgs.gov/projects/RM_snowpack/

http://www.wcc.nrcs.usda.gov/snow/

http://www.fs.fed.us/air/ 


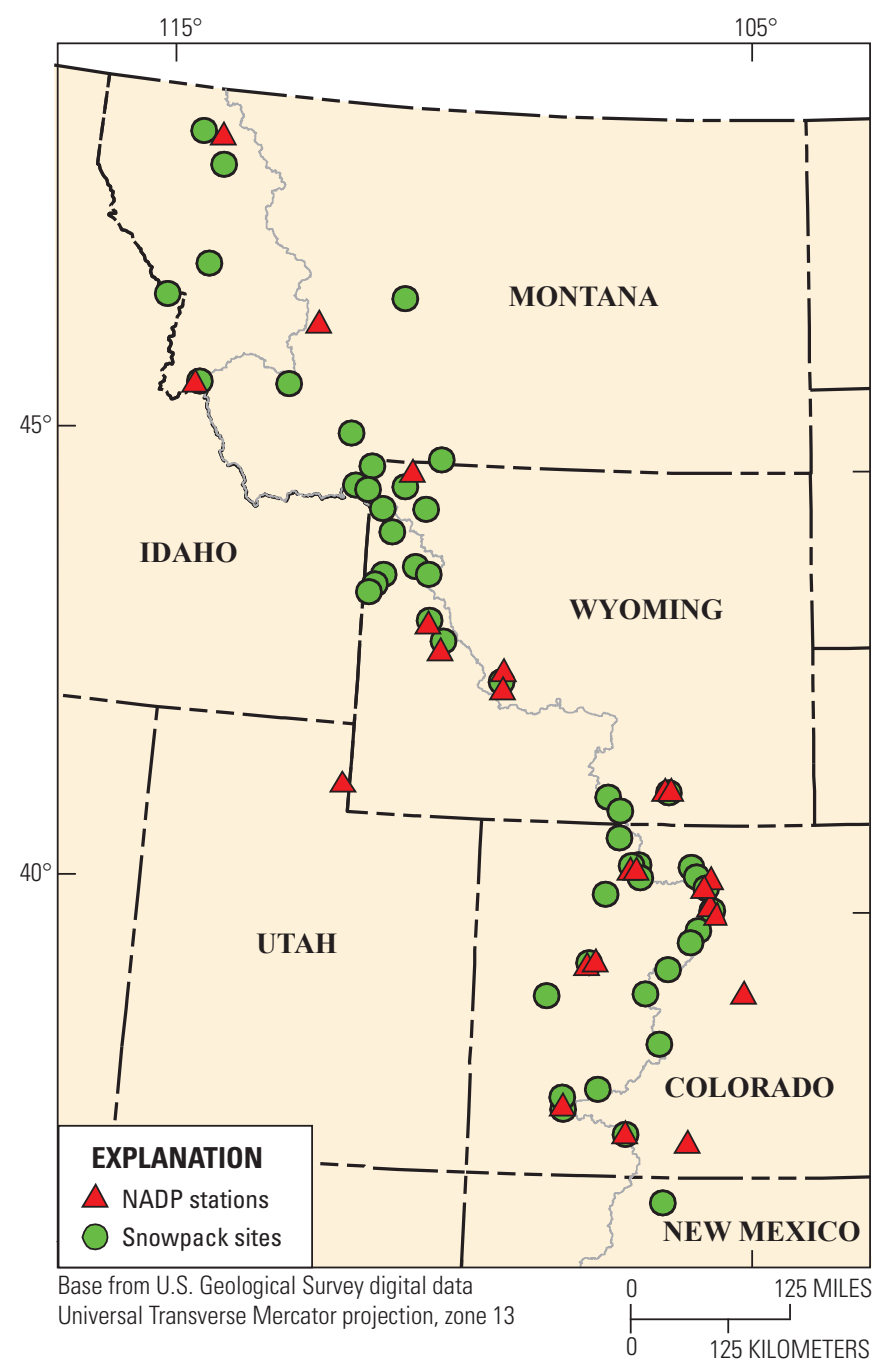

Figure 2. National Atmospheric Deposition Program (NADP) wet-deposition stations and snowpack-sampling sites in the Rocky Mountain region, 2010.

with studies in the Eastern United States that have attributed declines in precipitation sulfate to emissions reductions established under the 1990 Clean Air Act Amendments (Driscoll and others, 2003; Stoddard and others, 2003; Burns and others, 2006).

Trends in nitrogen species (nitrate and ammonium) were not as widespread as those observed for sulfate. About onehalf of NADP stations showed upward trends in ammonium concentrations, and only one station showed a downward trend in nitrate. The largest increases in ammonium concentrations

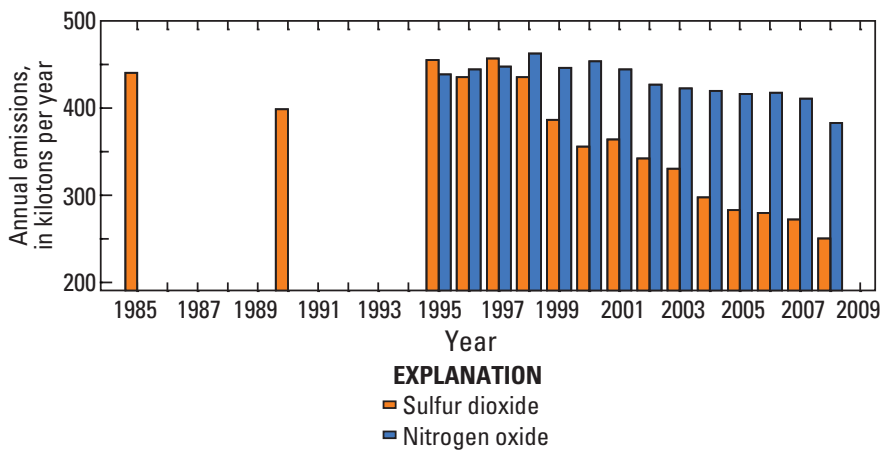

Figure 3. Trends in sulfur dioxide and nitrogen oxide emissions from stationary sources in the Rocky Mountain region. generally occurred after 1998 (fig. 4) and at NADP stations closest to agricultural and urban areas in eastern Colorado. The results are consistent with nationwide increases in ammonium concentrations at NADP stations from 1985 to 2004 (Lehman and others, 2007). Snowpack sites showed a lack of trends for nitrate and also for ammonium, with only 2 out of 48 stations having upward trends. When snowpack sites were analyzed as a group, however, significant upward trends in ammonium were detected for the Rocky Mountain region, consistent with NADP stations. Trends in nitrate and ammonium deposition appeared to be inconsistent with emission trends; however, due to the high degree of uncertainty associated with available emission inventories, it is difficult to make a direct comparison at this time.

\section{How has climate varied in the region?}

Air temperatures have been increasing since the early 1990s in mountainous areas, whereas no long-term change was evident for precipitation.

Analysis of climate records indicates that annual mean minimum air temperatures have increased about $0.7^{\circ} \mathrm{C}$ per decade in mountainous areas of the region with slightly stronger trends at more southern stations in Colorado compared to those to the north in Wyoming and Idaho (fig. 5). These observed trends in air temperature appear to be consistent with global trends (Intergovernmental Panel on Climate Change, 2007), and may indicate that human-induced warming could have a measurable effect on aquatic ecosystems in some high-elevation areas of the Rocky Mountains. Generally, trends in annual precipitation were not evident from 1990 to 2006, although there was a notable decrease in precipitation in the middle part of the record caused by wetter than average years during 1995 to 1997 and drier years during 2001 to 2004 (fig. 6).

\section{How have high-elevation lakes responded to changes in deposition and climate?}

Despite widespread declines in sulfate deposition, fewer than 20 percent of lakes appeared to be responding to the deposition trend. About one-third of lakes showed increasing sulfate concentrations, which was attributed to climate-related factors.

Despite widespread declines in sulfate deposition, decreases in lake-water sulfate concentrations were only observed for lakes in the Zirkel/Flat Tops Mountains (fig. 7). Sulfur isotopic data indicate lake-water sulfate in these two areas is dominated by deposition sources, indicating that lake chemistry in these areas is responding to regional reductions in $\mathrm{SO}_{2}$ emissions and atmospheric sulfate deposition. About one-third of lakes had significant upward trends in sulfate concentrations, which were opposite to the trend in deposition. Increasing lake-water concentrations were partly explained by a decline in precipitation between 1995 and 2002, which may have increased groundwater sources to some lakes. The increase in air temperature also may have been a factor. Warming in alpine areas might increase rates of mineral weathering or cause enhanced melting of ice features, such as permafrost, rock glaciers, and glaciers. 

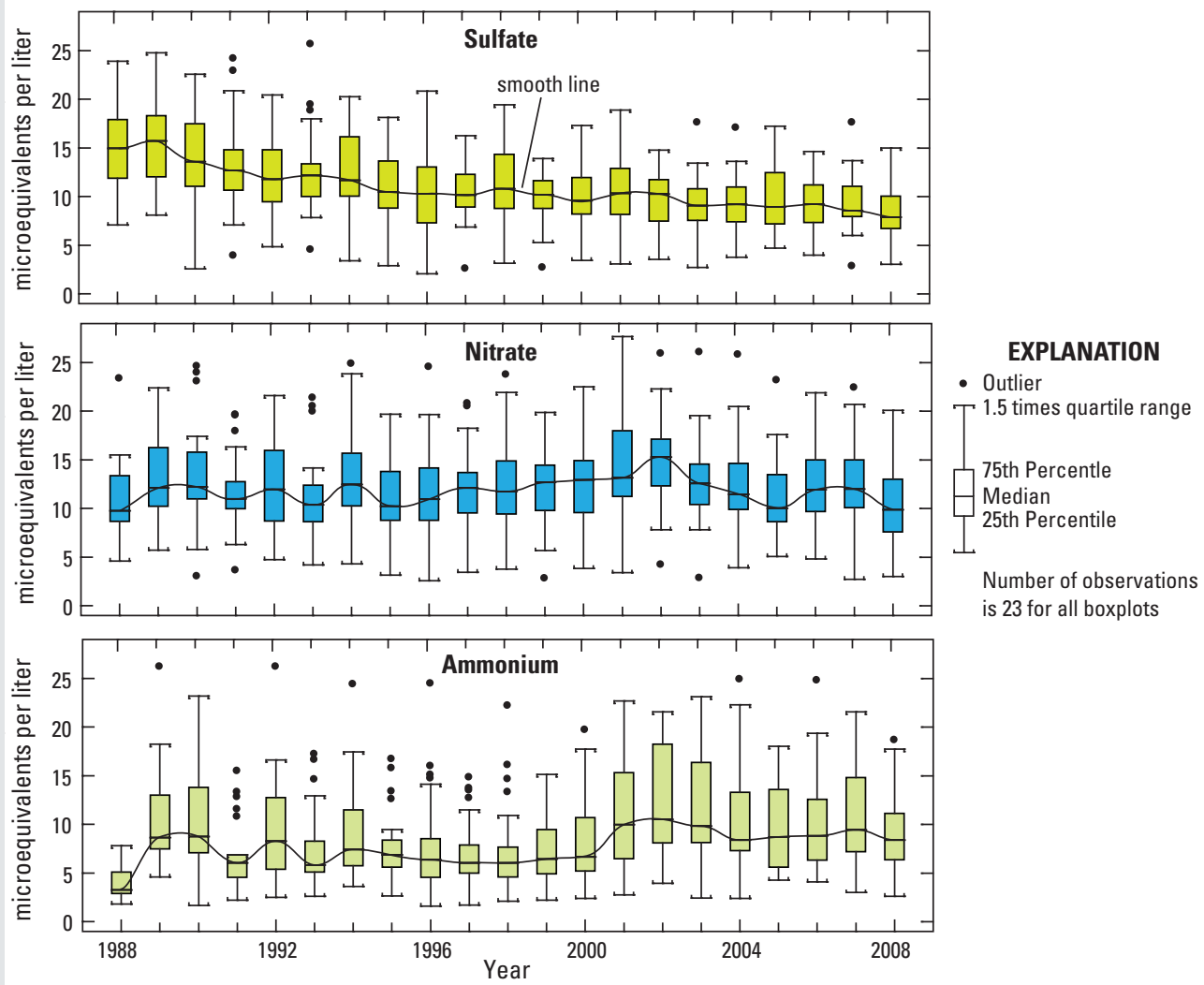

is 23 for all boxplots

Figure 4. Box plots showing variation in annual volume-weighted mean concentrations of sulfate, nitrate, and ammonium at 23 high-elevation stations in Colorado, Montana, Utah, and Wyoming, in the National Atmospheric Deposition Program, from 1988 to 2008.

Few trends were detected in lake-water nitrate because concentrations at most lakes were at or near the analytical reporting limit during the growing season owing to biological uptake. Four lakes in Colorado east of the Continental Divide showed upward trends in nitrate concentrations, which might reflect a response to increases in atmospheric ammonium deposition. Alternatively, some high-elevation areas may be

Figure 5. Range of anomalies in annual mean minimum air temperature in Rocky Mountain region, 1990-2006.

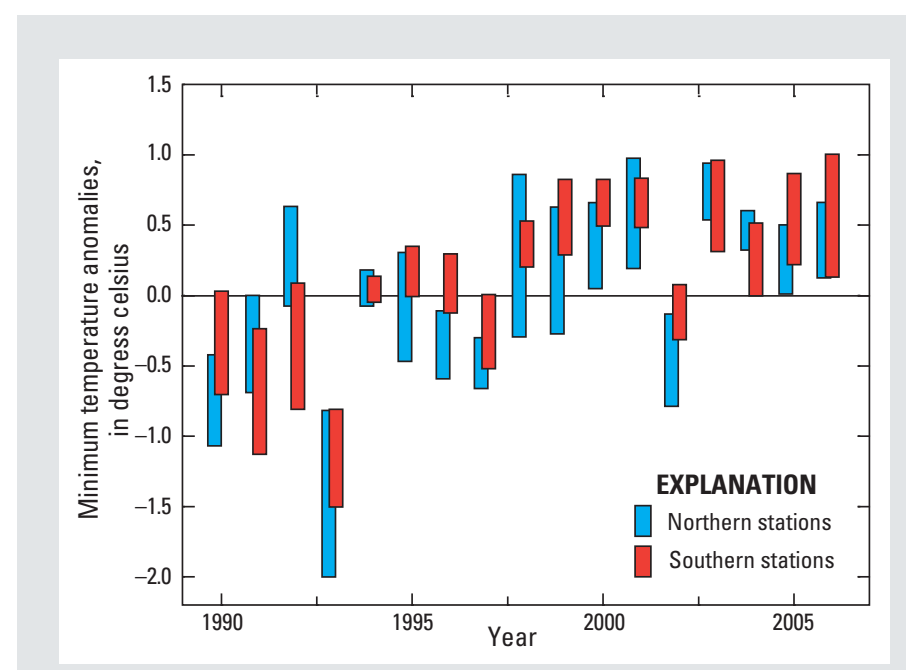

reaching an early stage of nitrogen saturation, and nitrate may be starting to leach to surface water. Short-term spikes in nitrate concentrations were observed at some lakes following a regional drought in 2002. This response may indicate that changes in climate, such as increased frequency of drought, could exacerbate the effects of nitrogen deposition on highelevation lakes. 


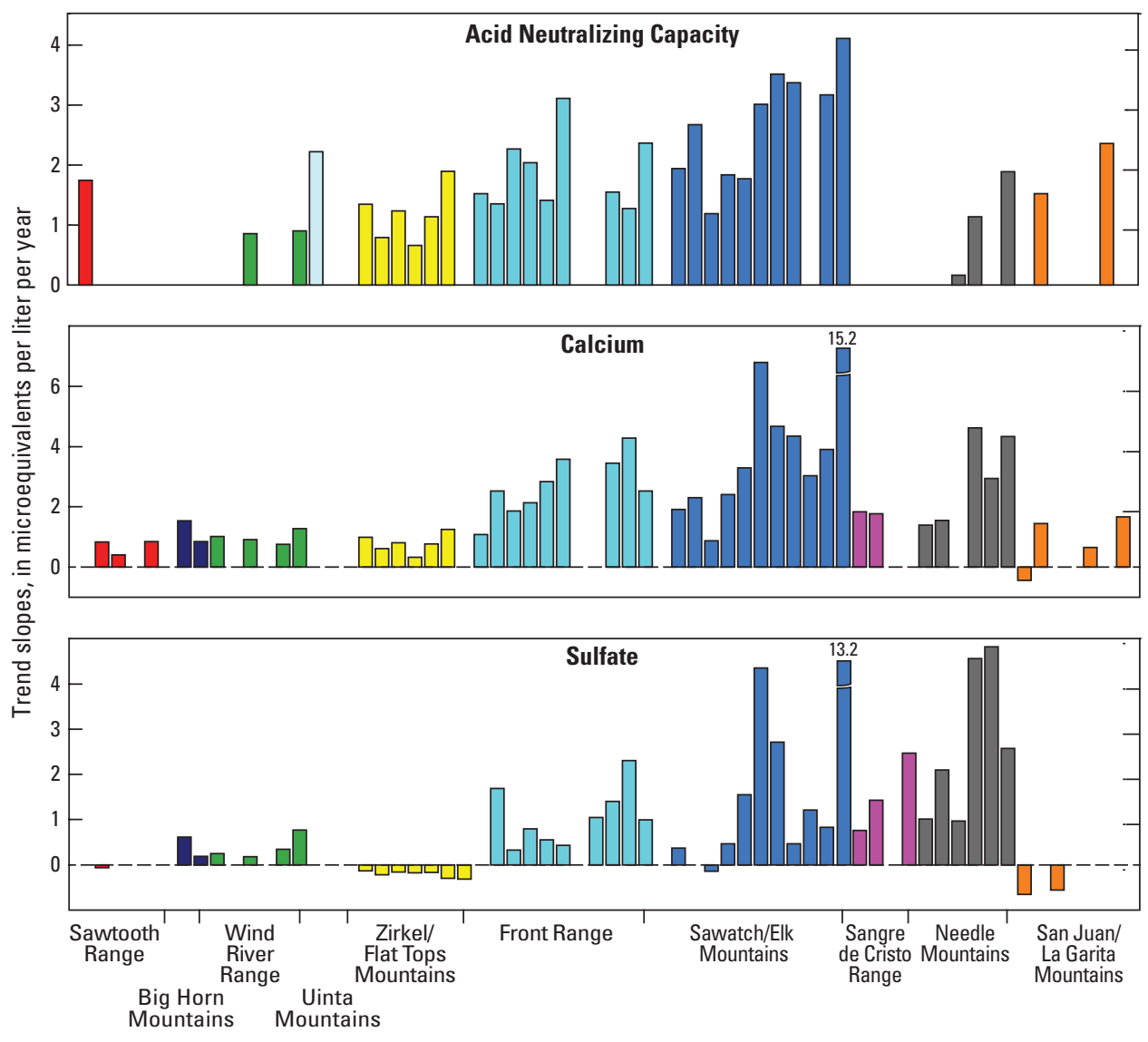

Figure 7. Concentration trends of selected dissolved constituents in the 64 study lakes grouped by major mountain range, 1993-2009.

Regardless of the mechanisms, climate-induced chemical changes will confound the ability to detect the response of highelevation lakes to future changes in anthropogenic emissions of sulfur and nitrogen. Such climate-related effects need to be taken into consideration by resource managers when evaluating new emission sources, as well as in the development and application of critical loads for managing sulfur and nitrogen air contaminants.

\section{Conclusions and Implications}

- As a result of efforts to reduce $\mathrm{SO}_{2}$ emissions from large point sources, sulfate and acidity in precipitation are decreasing in high-elevation areas of the Rocky Mountains. In response, sulfate concentrations declined in lakes with no internal sulfate sources, indicating emission control programs have had a positive effect on AQRVs in the most sensitive areas.

- Although there were widespread declines in sulfate deposition, about one-third of the study lakes showed upward trends in sulfate concentrations. Lakes showing increasing sulfate were determined to have contributions of sulfate from geologic sources. Increasing air temperatures may have been a factor driving mineral weathering in these areas, as well as a notable decrease in precipitation in the middle of the record caused by wetter than average years during 1995 to 1997 and drier years during 2001 to 2004. These results indicate how climate variation may mask trends resulting from improvements in atmospheric deposition of contaminants.

- In contrast to sulfate, deposition trends for nitrogen species were not as widespread. Ammonium deposition appeared to be increasing in the region, particularly at sites closest to urban and agricultural areas. Surface-water nitrate was less than analytical reporting levels at most lakes, indicating atmospherically deposited nitrogen is still largely retained by aquatic and terrestrial biota. However, several lakes east of the Continental Divide in Colorado showed evidence of increasing nitrate concentrations, perhaps indicating that

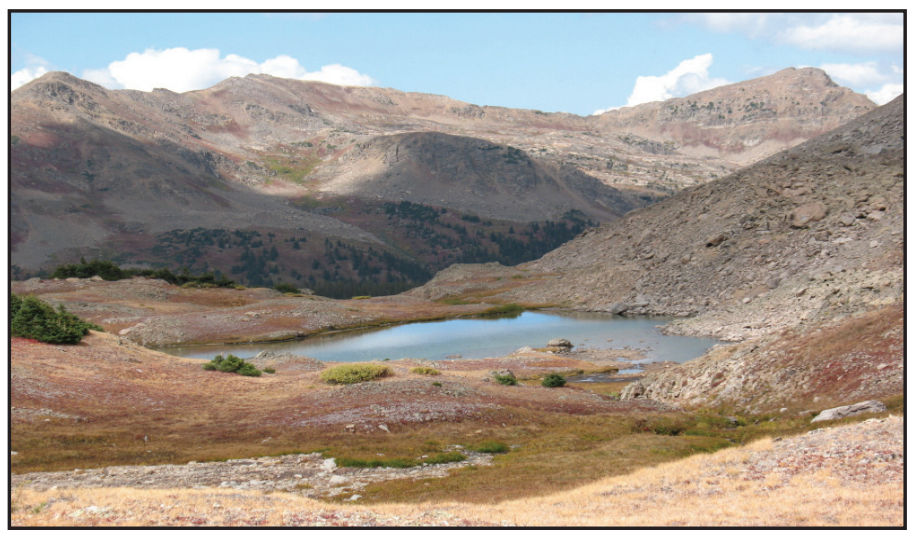



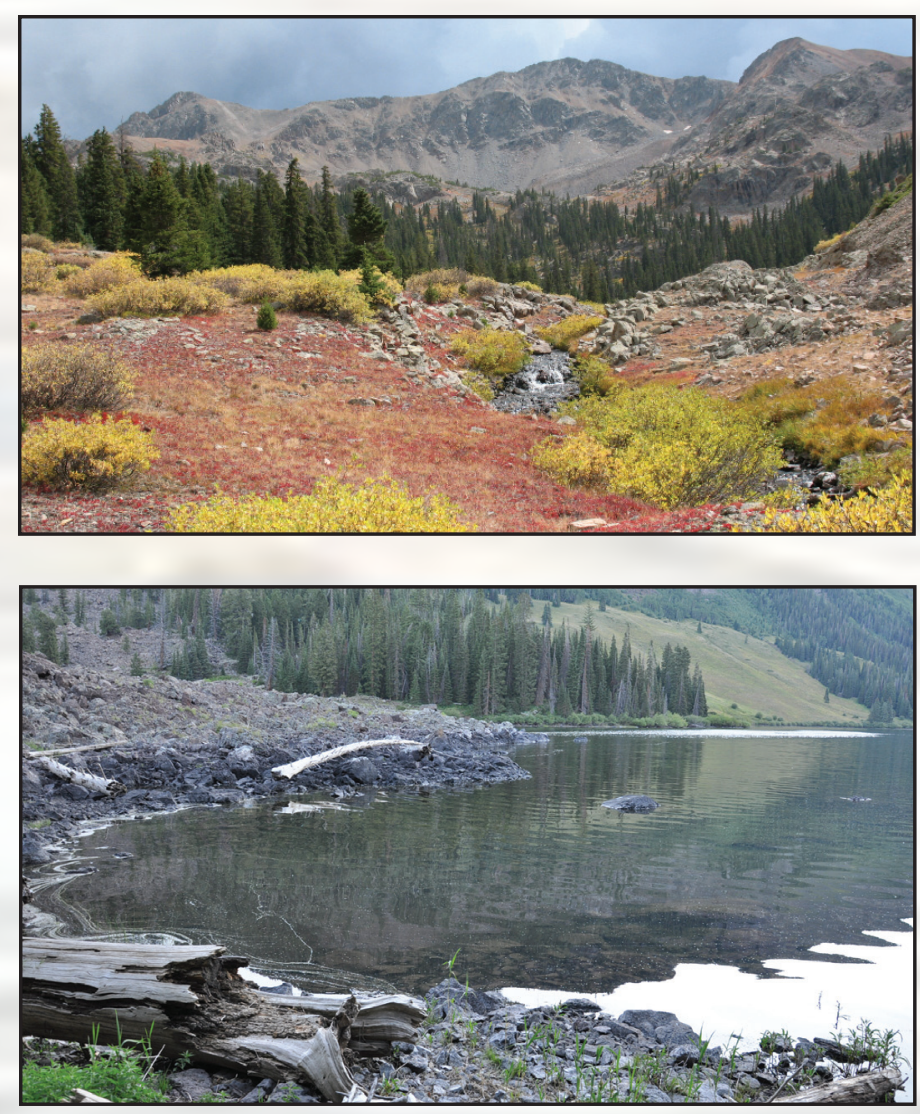

these sensitive watersheds are beginning to respond to years of prolonged deposition by exhibiting symptoms of nitrogen saturation. Many of these systems may be at or near the tipping point or critical load for nitrogen, and continued monitoring will be critical for detecting any changes in water quality that might negatively affect aquatic biota.

- Continued monitoring of atmospheric deposition is a key component of understanding the effects of air contaminants on lakes and other AQRVs. Although the National Atmospheric Deposition Program (NADP) provides year-round monitoring at 250 sites nationally, high-elevation sites are sparse. The USGS Rocky Mountain Snowpack Network (RMSN) provides substantially greater geographic coverage of the Rocky Mountain region (fig. 2). The high-elevation snowpack is important because it accumulates 2-3 times the annual precipitation compared to low-elevation sites. Further, snowpacks provide a more complete estimate of wintertime deposition because they capture wet and dry deposition. Continuation of both networks (NADP and RMSN) is needed to effectively monitor deposition chemistry in high-elevation areas.

- The response of surface-water chemistry to environmental change often is difficult to evaluate because of the scarcity of long-term monitoring networks. Long-term records provide the foundation for understanding trends in ecological responses (Stoddard and others, 2003). There are few continuous waterquality records for high-elevation lakes in the Western United States, and the Forest Service dataset provided a unique opportunity to analyze air pollution effects for the Rocky Mountain region. Continued monitoring of these lakes is critical in assessing the success of present and future air contaminant control measures on the condition of AQRVs in federally protected wilderness areas.

\section{References Cited}

Burns, D.A., 2004, The effects of atmospheric nitrogen deposition in the Rocky Mountains of Colorado and southern Wyoming, USAA critical review: Environmental Pollution, v. 127, p. 257-269.

Burns, D.A., McHale, M.R., Driscoll, C.T., and Roy, K.M., 2006, Response of surface water chemistry to reduced levels of acid precipitation - Comparison of trends in two regions of New York, USA: Hydrological Processes, v. 20, p. 1611-1627.

Driscoll, C.T., Driscoll, K.M., Roy, K.M., and Mitchell, M.J., 2003, Chemical response of lakes in the Adirondack region of New York to declines in acidic deposition: Environmental Science \& Technology, v. 37, p. 2036-2042.

Eastern Research Group, Inc., 2006, Wrap point and area source emissions projections for the 2018 base case inventory, version 1 , prepared for Western Governors' Association and The Western Regional Air Partnership, Stationary Sources Joint Forum, available at http://www.swcleanair.org/gorgedata/WRAP_EI_AreaPointSources.pdf, accessed April 2010.

Helsel, D.R., Mueller, D.K., and Slack, J.R., 2006, Computer program for the Kendall family of trend tests: U.S. Geological Survey Scientific Investigations Report 2006-5275, 4 p.

Intergovernmental Panel on Climate Change, 2007, Climate change 2007-The physical science basis: Contribution of Working Group I to the Fourth Assessment Report of the Intergovernmental Panel on Climate Change, Cambridge University Press, 1009 p.

Lehmann, C.M., Bowersox, C., Larson, R.S., and Larson, S.M., 2007, Monitoring long-term trends in sulfate and ammonium in US precipitation - Results from the National Atmospheric Deposition Program/National Trends Network: Water Air Soil Pollution Focus 7, p. 59-66.

Mast, M.A., and Ingersoll, G.P., 2011, Trends in lake chemistry in response to atmospheric deposition and climate in selected Class I wilderness areas in Colorado, Idaho, Utah, and Wyoming, 1993-2009: U.S. Geological Survey Scientific Investigations Report 2011-5123.

Peterson, J., Schmoldt, D., Peterson, D., Eilers, J., Fisher, R., and Bachman, R., 1992, Guidelines for evaluating air pollution impacts on class I wilderness areas in the Pacific Northwest: Portland, Ore., Pacific Northwest Research Station, U.S. Department of Agriculture General Technical Report PNW-GTR-299, 83 p.

Peterson, D.L., Sullivan, T.J., Eilers, J.M., and Brace, S., 1998, Assessment of air quality and air pollutant impacts in National Parks of the Rocky Mountains and Northern Great Plains: Denver, U.S. Department of the Interior, National Park Service, Air Resources Division.

Stoddard, J.L., Kahl, J.S., Deviney, F.A., DeWaller, D.R., Driscoll, C.T., Herlihy, A.T., Kellogg, J.H., Murdoch, P.S., Webb, J.R., and Webster, K.E., 2003, Response of surface water chemistry to the Clean Air Act Amendments of 1990: Research Triangle Park, U.S. Environmental Protection Agency, EPA/620/R-03/001NC.

\section{—By M. Alisa Mast, Colorado Water Science Center}

For more information please contact

Center Director

USGS Colorado Water Science Center

Box 25046, Mail Stop 415

Lakewood, CO 80225-0046

(303) 236-6900 